\title{
LETTER \\ Implementation of Smart Dressing Systems Based on Flexible pH Sensors Using PET Films
}

\author{
Seok-Oh YUN ${ }^{\dagger, \dagger \dagger a)}$, Jung Hoon LEE ${ }^{\dagger \dagger \dagger b)}$, Nonmembers, Jin LEE LE $^{\dagger \dagger \dagger c)}$, Member, \\ and Choul-Young $\mathrm{KIM}^{\dagger \mathrm{d})}$, Nonmember
}

\begin{abstract}
SUMMARY In this paper, a smart dressing system was implemented based on flexible $\mathrm{pH}$ sensors that can monitor the infection of a wounded area by tracking the $\mathrm{pH}$ value of the area. Motivated by the fabrication process widely used for semiconductors, the flexible $\mathrm{pH}$ sensor fabrication process was devised with a polyester (PET) film and a Si wafer, which deposits $\mathrm{Au}$ and $\mathrm{Ag}$ on a PET film. Because the electrodes are comprised of a working electrode and a reference electrode, the reference electrode was fabricated by synthesizing the Polyaniline (PANI) on $\mathrm{Ag} / \mathrm{AgCl}$, while the $\mathrm{pH}$ sensor has four channels to evenly measure the $\mathrm{pH}$ value in a wide area. The smart dressing system was constructed with four $\mathrm{pH}$ sensors, a single temperature sensor, a level shifter, a regulator, an analog-to-digital converter (ADC), and a monitoring PC. The measurement results show that our smart dressing system has a size of $5 \times 5 \mathrm{~cm}^{2}$ and can monitor the $\mathrm{pH}$ value range found in [3,9] with a sensitivity slope of $50 \mathrm{mV} / \mathrm{pH}$.

key words: pH sensor, $p H$ meter, smart dressing, wound infection
\end{abstract}

\section{Introduction}

In recent years, $\mathrm{pH}$ sensors have been widely used for various purposes in laboratories, clinics, and industries [1]-[4] because they provide a logarithmic measure of hydrogen ion concentration. As many biological and chemical reactions are dependent on $\mathrm{pH}$ level, $\mathrm{pH}$ sensors play important roles in human health care, water quality, food quality, etc.

Nowadays, flexible/wearable sensors have attracted great attention, especially for human health monitoring [5][10]. For example, the authors of [10] devised bandagebased $\mathrm{pH}$ sensors for real-time wound $\mathrm{pH}$ monitoring. Also, the authors of [11] developed textile-based $\mathrm{pH}$ sensors to measure the $\mathrm{pH}$ of sweat and found that sweating rate and $\mathrm{pH}$ values are correlated.

One of the most popular treatments for wounds is the wet environment treatment, which maintains skin exudates

Manuscript received March 15, 2019.

Manuscript publicized April 23, 2019.

${ }^{\dagger}$ The authors are with the Department of Electronics, Chungnam National University, Daejeon, 34134, South Korea.

${ }^{\dagger}$ The author is with National Nanofab Center, Daejeon 34141 , South Korea.

${ }^{\dagger \dagger}$ The author is with the Department of Electronics Engineering and Applied Communications Research Center, Hankuk University of Foreign Studies, Yongin 17035, South Korea.

${ }^{\dagger+\dagger}$ The author is with the Department of Information and Communication, Pyeongtaek University, Pyeongtaek, 17869, South Korea.

a) E-mail: soyun@nnfc.re.kr

b)E-mail: tantheta@hufs.ac.kr

c)E-mail: mygenie79@ptu.ac.kr

d) E-mail: cykim@cnu.ac.kr (Corresponding author)

DOI: 10.1587/transinf.2019EDL8056

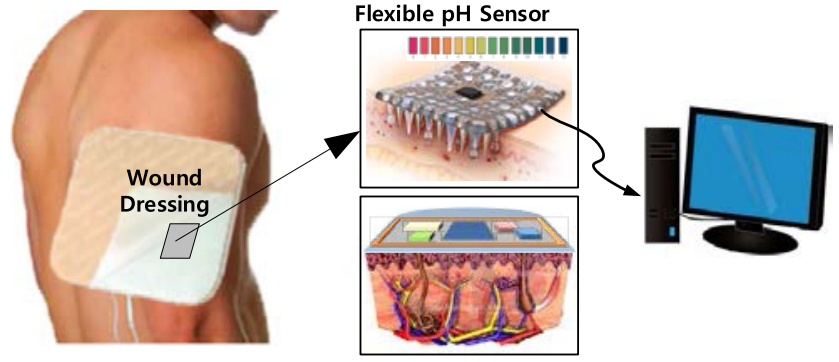

Fig. 1 Concept of the smart dressing for monitoring infected wounds.

and so rapidly heals the wounded area without scarring. In some cases, however, the wet environment may cause some trouble by allowing growth of bacteria, which can even lead to patient death by infection. Therefore, medical doctors replace dressings frequently to avoid infection. Although infection of a wounded area can be fatal to the patient, smart dressings that monitor wounded areas have not been fully studied yet.

In this paper, a smart dressing system that monitors the infection of a wounded area was implemented. Our main contribution is to implement the smart dressing system that prevents the infection of a wounded area by monitoring the $\mathrm{pH}$ value of the area. In a normal stage, human skin is slightly acidic, with a $\mathrm{pH}$ value of 5.5. However, the $\mathrm{pH}$ value increases to 9 when the wounded area is infected. Thus, our smart dressing system monitors infection by observing $\mathrm{pH}$ value of wounded area. For ease of attachment to the skin, our smart dressing system adopts flexible $\mathrm{pH}$ sensors.

First, motivated by the fabrication process widely used for semiconductors, the flexible $\mathrm{pH}$ sensor fabrication process is proposed with a PET film and Si wafer. Then, the smart dressing system is constructed with four $\mathrm{pH}$ sensors, a single temperature sensor, a level shifter, a regulator, an analog-to-digital converter (ADC), and a monitoring PC.

This paper is organized as follows. In Sect. 2, we explain the implementation of our smart dressing system including the overall architecture, the flexible sensor design, and the system integration on PCB. In Sect. 3, we evaluate our smart dressing system. Then, Sect. 4 concludes our paper. 


\section{Implementation of a Smart Dressing System Based on Flexible pH Sensors}

\subsection{Overall Architecture}

The overall architecture of our smart dressing system based on flexible $\mathrm{pH}$ sensors is illustrated in Fig. 2. Our smart dressing system consists of four $\mathrm{pH}$ sensors, a single temperature sensor, a level shifter, a regulator, an analog-to-digital converter (ADC), and a monitoring PC. In our smart dressing system, to more precisely monitor the $\mathrm{pH}$ values of a wide wounded area, four identical $\mathrm{pH}$ sensors were used.

The operation of our smart dressing system is as follows.

The $\mathrm{pH}$ sensor first measures the $\mathrm{pH}$ value and produces a corresponding small voltage signal. Then, the amplifier and the level shifter boost the signal to the operating range, and the ADC digitizes the voltage value. Finally, the $\mathrm{PC}$ reads the digitized $\mathrm{pH}$ value via the USB interface.

Similarly, the PC obtains the temperature using the temperature sensor, the amplifier, and the ADC. In this case, negative temperature coefficients (NTC) were adopted: the ADC in the micro-controller unit (MCU) reads the voltage of the reference resistor. Note that both of the sensing values (i.e., the $\mathrm{pH}$ and the temperature values) can be calibrated from the sensors' statistic features.

\subsection{The Proposed pH Sensor Design for Flexibility}

Our smart dressing system adopts flexible $\mathrm{pH}$ sensors for ease of attachment to the body. To make the $\mathrm{pH}$ sensor flexible, fabrication processes were devised that use both a $\mathrm{Si}$ wafer and a PET film, as illustrated in Fig. 3.

The fabrication processes of our flexible $\mathrm{pH}$ sensor are as follows.

(a) A glue layer, which is a thermal release tape, is coated on the Si substrate using a spin coater.

(b) A PET film is attached onto spin coating on the Si wafer, with an ultraviolet (UV) curing process.

(c)-(d) Patterned stencil mask is drawn on the PET file and filled with Ti/Au to thicknesses of $200 \AA / 2,000 \AA$, respectively.

(e) Once the deposition of $\mathrm{Ti} / \mathrm{Au}$ is complete, the stencil mask is removed.

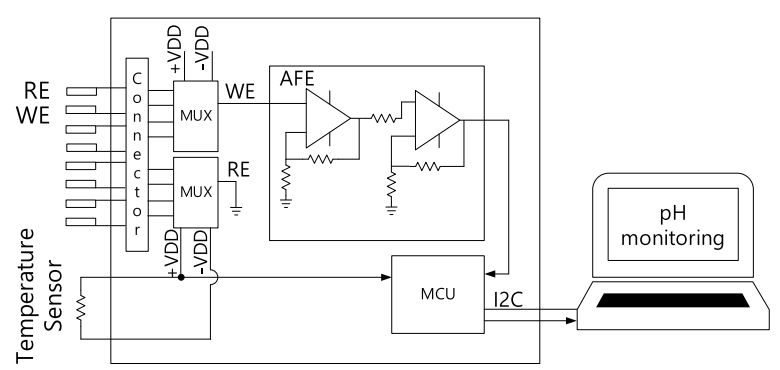

Fig. 2 The block diagram of our smart dressing system. (f) A Ti/Ag layer is deposited to thickness of $200 \AA / 2,000 \AA$, and sensor structure is obtained.

(g) The PET film is removed from the Si wafer, and the flexible sensor part is obtained.

After obtaining the flexible sensor structure, $\mathrm{AgCl}$ was coated on both the working electrode and the reference electrode.

Our $\mathrm{pH}$ meter was evaluated with a simulation block whose schematic diagram is depicted in Fig. 4. The simulation block is comprised of an operational amplifier (OpAmp) with a level shifter. In this case, the sensitivity is $50 \mathrm{mV} / \mathrm{pH}$. Also, the input signal is amplified 30 times at OpAmp and then transferred to the level shifter. In Table 1, the sensing voltages and the final output voltages are sum-

(a)

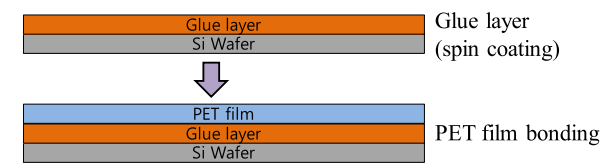

(c)

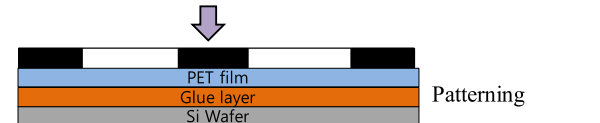

(d)

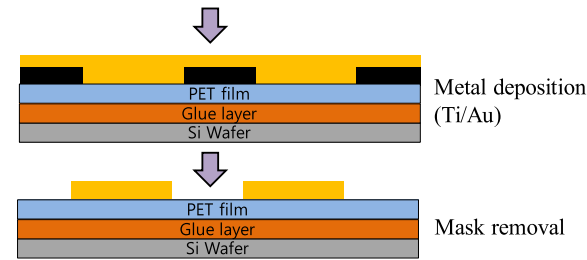

(f)

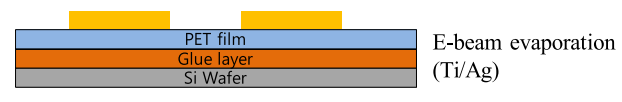

(g)
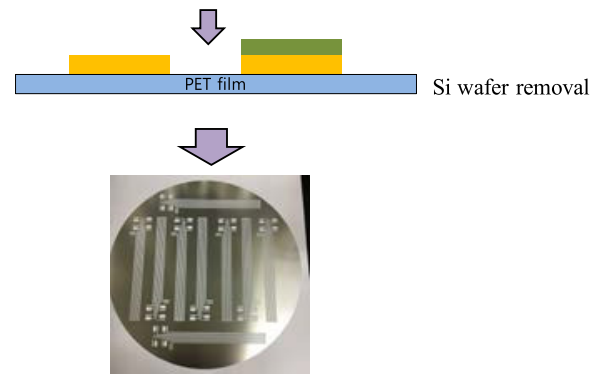

Fig. 3 Fabrication processes for $\mathrm{pH}$ sensor with a Si wafer and a PET film.

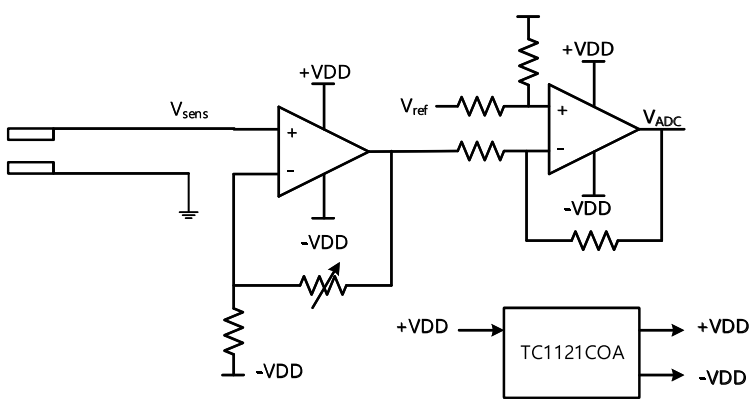

Fig. 4 The schematic diagram for the $\mathrm{pH}$ meter evaluation. 
Table 1 The sensing voltages and the final output voltages according to the various $\mathrm{pH}$ values

\begin{tabular}{ccc|ccc}
\hline $\mathrm{pH}$ & Vsens $(\mathrm{mV})$ & Vout $(\mathrm{V})$ & $\mathrm{pH}$ & Vsens $(\mathrm{mV})$ & Vout $(\mathrm{V})$ \\
\hline 0 & 414.14 & 0.172 & 8 & -59.16 & 1.591 \\
\hline 1 & 354.96 & 0.349 & 9 & -118.3 & 1.769 \\
\hline 2 & 295.80 & 0.527 & 10 & -177.5 & 1.946 \\
\hline 3 & 236.64 & 0.704 & 11 & -236.6 & 2.123 \\
\hline 4 & 177.48 & 0.881 & 12 & -295.8 & 2.301 \\
\hline 5 & 118.32 & 1.059 & 13 & -354.9 & 2.478 \\
\hline 6 & 59.16 & 1.236 & 14 & -414.1 & 2.656 \\
\hline 7 & 0 & 1.414 & - & - & - \\
\hline
\end{tabular}

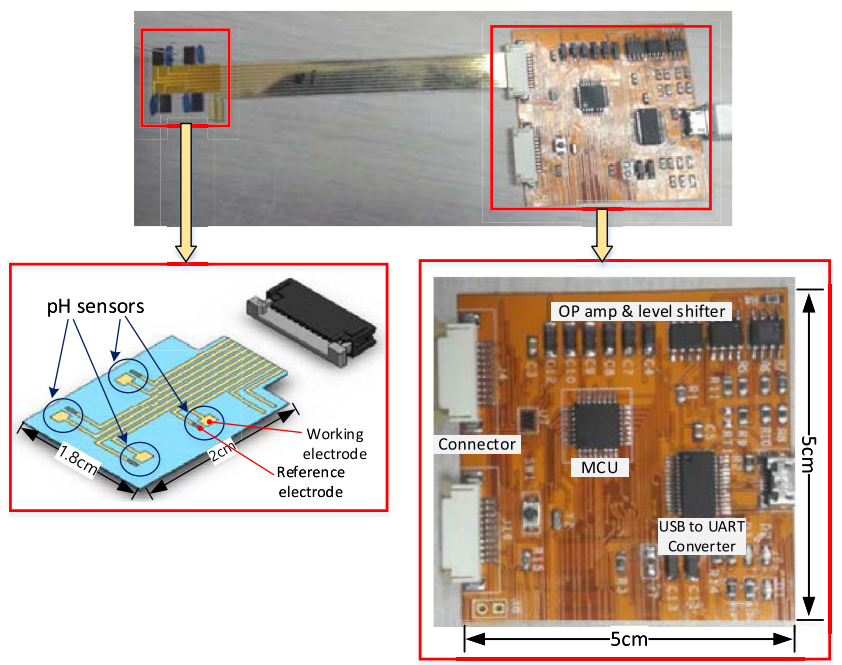

Fig.5 The system integration on PCB for our smart dressing system.

marized with respect to the $\mathrm{pH}$ values. For adjustment of the $\mathrm{pH}$ values for the temperature, the Nernst equation was used, which represents the relationship between $\mathrm{pH}$ value temperature.

\subsection{System Integration on PCB}

This section explains the system integration on PCB for our smart dressing system. Figure 6 shows the final product of our smart dressing system. As we showed in Fig. 5, there are four $\mathrm{pH}$ sensors, each of which has working and reference electrodes. Then, the sensors are connected to the $\mathrm{pH}$ meter with a wire bonding process. In this case, the $\mathrm{pH}$ meter is comprised of two layers for PCB design. The first layer contains the OpAmp, the level shifter, and the temperature sensor, while the second layer contains MCU and USB, with a universal asynchronous receiver-transmitter (UART) converter.

To evaluate the sensitivity of our flexible $\mathrm{pH}$ sensors, the open circuit voltage between the polyaniline working electrode and the $\mathrm{Ag} / \mathrm{AgCl}$ reference electrode was measured. The voltage value measured at the $\mathrm{pH}$ sensor becomes the input of the OpAmp and the level shifter. In this case, the OpAmp amplifies the output signal of each $\mathrm{pH}$ sensor to the operating voltage, and the level shifter centers the amplified signal at $3.3 \mathrm{~V}$. Then, the analog signal passes the $\mathrm{ADC}$, and so is converted to a digital signal.

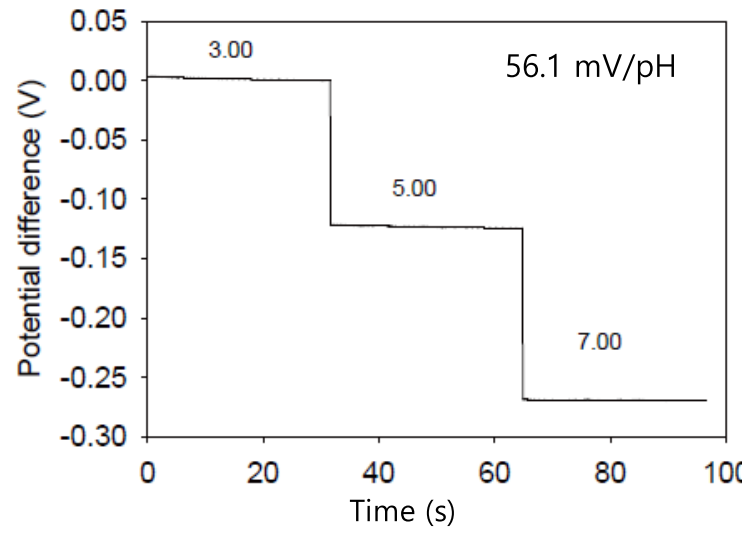

(a) The potential difference according to $\mathrm{pH}$ changes over time

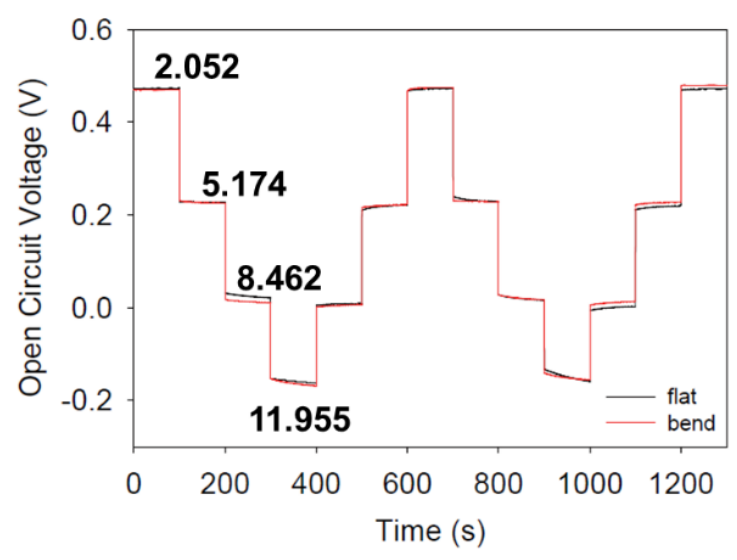

(b) The open circuit voltages for a $\mathrm{pH}$ value pattern

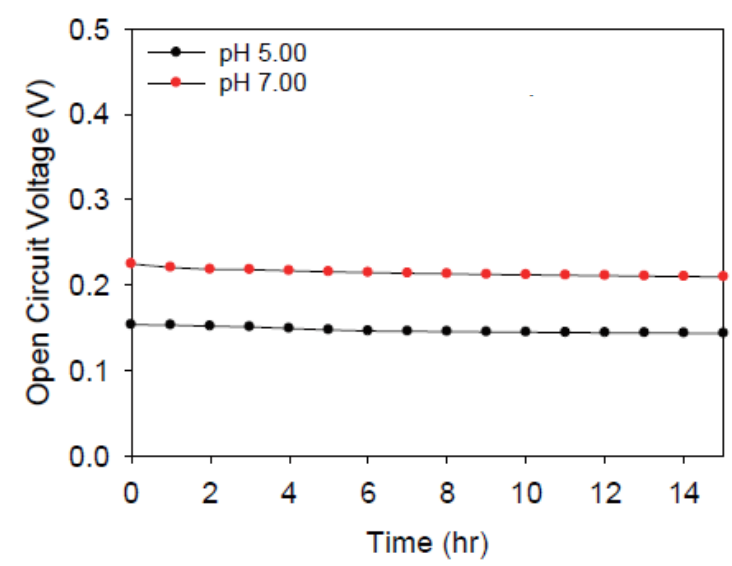

(c) The stabilities of open circuit voltages at $\mathrm{pH} 5$ and $\mathrm{pH} 7$ over time

Fig. 6 Various measurements for our smart dressing system.

Figure 6 shows the electrical characteristics of our $\mathrm{pH}$ flexible sensors. In Fig. 6(a), the changes of the potential difference were measured by varying the $\mathrm{pH}$ values from 3 to 5 to 7 . In Fig. 6(a), we can check that our pH sensor detects potential differences well when dipped in vari- 
ous solutions of different pH value. In Fig. 6(b), to check the reproducibility, the open circuit-voltages are shown as derived from the repeated $\mathrm{pH}$ value patterns over time. For the reproducibility test, the $\mathrm{pH}$ values were varied with the patterns of $[2.052,5.174,8.462,11.955]$ and the open circuit voltages were measured when the flexible $\mathrm{pH}$ sensors were flat and bent, respectively. As can be seen in Fig. 6 (b), differences among measured $\mathrm{pH}$ values corresponding to the same input $\mathrm{pH}$ value are far less than $\mathrm{pH} 0.1$, which ensures that our smart dressing system produces a reproducible open-circuit voltage for every $\mathrm{pH}$ level. Figure 6 (c) shows the open circuit voltages measured over 15 hours at $\mathrm{pH}$ values of 5 and 7. As can be seen in Fig. 6 (c), our smart dressing system shows almost the same open circuit voltage for each $\mathrm{pH}$ value over a long period. In this case, the voltage changes are less than $0.64 \mathrm{mV}$ and $0.49 \mathrm{mV}$ per hour for $\mathrm{pH}$ values of 5 and 7 , respectively.

\section{Conclusion}

In this paper, a smart dressing system was implemented based on flexible $\mathrm{pH}$ sensors with a PET film and a Si wafer that can monitor the infection of a wounded area in real time by tracking the $\mathrm{pH}$ value of that wounded area. Flexible $\mathrm{pH}$ sensor fabrication process was devised to deposit $\mathrm{Au}$ and $\mathrm{Ag}$ on a PET film. Then, we constructed the smart dressing system consisting of four $\mathrm{pH}$ sensors, a single temperature sensor, a level shifter, a regulator, an ADC, and a monitoring PC. The measurement results show that our smart dressing system performed well. Our $\mathrm{pH}$ sensing system can be improved by adopting wireless communication techniques such as Bluetooth and RFID and by adopting flexible batteries or connecting it to a smartphone for portability and ease of use. These are our on-going research topics.

\section{Acknowledgments}

This work was supported by the Technology Innovation Program $(10054505,10077629)$ funded by the Ministry of Trade, industry \& Energy (MOTIE), Korea.

\section{References}

[1] D. Wencel, T. Abel, and C. McDonagh, "Optical chemical pH sensors," Anal. Chem., vol.86, no.1, pp.15-29, 2014.

[2] T. Berbasova, M. Nosrati, C. Vasileiou, W. Wang, K.S.S. Lee, I. Yapici, J.H. Geiger, and B. Borhan, "Rational design of a colorimetric $\mathrm{pH}$ sensor from a soluble retionoic acid chaperone," J. Am. Chem. Soc., vol.135, no.43, pp.16111-16119, 2013.

[3] Y. Qin, H.-J. Kwon, M.M.R. Howlader, and M.J. Deen, "Microfabricated electrochemical $\mathrm{pH}$ and free chlorine sensors for water quality monitoring: Recent advances and research challenges," RSC Adv., vol.5, no.85, pp.69086-69109, 2015.

[4] J. Chu, Y. Zhao, S.-H. Li, H.-Q. Yu, G. Liu, and Y.-C. Tian, "An integrated solid-state $\mathrm{pH}$ microelectrode prepared using microfabrication," Electrochim. Acta, vol.152, pp.6-12, 2015.

[5] T. Guinovart, G. Valdés-Ramírez, J.R. Windmiller, F.J. Andrade, and J. Wang, "Bandage-based wearable potentiometric sensor for monitoring wound pH," Electroanalysis, vol.26, no.6, pp.1345-1353, 2014.

[6] L. Santos, J.P. Neto, A. Crespo, D. Nunes, N. Costa, I.M. Fonseca, P. Barquinha, L. Pereira, J. Silva, R. Martins, and E. Fortunato, "WO 3 nanoparticle-based conformable pH sensor," ACS Appl. Mater. Interfaces, vol.6, no.15 pp.12226-12234, 2014.

[7] W. Gao, S. Emaminejad, H.Y.Y. Nyein, S. Challa, K. Chen, A. Peck, H.M. Fahad, H. Ota, H. Shiraki, D. Kiriya, D.-H. Lien, G.A. Brooks, R.W. Davis, and A. Javey, "Fully integrated wearable sensor arrays for multiplexed in situ perspiration analysis," Nature, vol.529, pp.509-514, 2016.

[8] A.J. Bandodkar, I. Jeerapan, and J. Wang, "Wearable chemical sensors: Present challenges and future prospects," ACS Sens., vol.1, no.5, pp.464-482, 2016.

[9] A.J. Bandodkar, V.W.S. Hung, W. Jia, G. Valdés-Ramírez, J.R. Windmiller, A.G. Martinez, J. Ramírez, G. Chan, K. Kerman, and J. Wang, "Tattoo-based potentiometric ion-selective sensors for epidermal pH monitoring," Analyst., vol.138, no.1, pp.123-128, 2013.

[10] A.J. Bandodkar, W. Jia, and J. Wang, "Tattoo-based wearable electrochemical devices: A review," Electroanalysis., vol.27, no.3, pp.562-572, 2015.

[11] D. Morris, S. Coyle, Y. Wu, K.T. Lau, G. Wallace, and D. Diamond, "Bio-sensing textile based patch with integrated optical detection system for sweat monitoring," Sens. Actuators B, vol.139, no.1, pp.231-236, 2009. 